\title{
An Exploratory Study of the Sexual Health Knowledge and Attitudes of Asian Male Student Sojourners in New Zealand
}

\author{
Saburo Omura, Michael Hills and Jane Ritchie* \\ University of Waikato
}

\begin{abstract}
This study looked into the sexual and general health attitudes of Asian male student sojourners in New Zealand. The following issues on sexual and general health were probed: level of awareness, views and perceptions, levels of knowledge, main sources of information, and cultural factors in seeking health information. An Internet-mediated survey was employed to gather data on this sensitive topic. Sixty-six participants from Waikato, Massey, Canterbury, and Otago Universities answered the questionnaire. In addition, key-informant interviews with health providers were conducted to provide additional data. Data from the survey indicated a high level of health awareness concerning both general and sexual health maintenance, but there was cultural reluctance to discuss health issues, especially sexual health. General and sexual health matters were regarded as highly personal and sensitive, which they discussed with close associates. Findings from the study suggest the need for culturally appropriate approaches to improve Asian male students' access to health services.
\end{abstract}

\footnotetext{
* We thank all those who participated in this research as well as those who assisted in carrying out this project. Saburo Omura extends his thanks to his colleagues at the clinical research laboratory for their support.
} 
In recent years, New Zealand has witnessed an increase in the number of international students, particularly fee-paying students (Ministry of Education, 2004). According to the Ministry of Education, foreign fee-paying students numbered 7,191 in 2000, 10,555 in 2001, 15,259 in 2002, 17,448 in 2003, and 14,477 in 2004, or a two-fold increase between 2000 and 2004. As of July 2004, nine out of ten international students (93.6 percent) came from Asia.

The surge in the number of international students presents opportunities and challenges for New Zealand as a destination country. On the one hand, the presence of many Asian students is viewed as economically valuable; on the other hand, concerns about their welfare in general, and their sexual health in particular, have been raised (The New Zealand Herald 3 April 2002). The increase in abortion rates among Asians in New Zealand, which include residents as well as non-residents, has been noted. In particular, the abortion rates for Asian females below 25 years old significantly increased (Statistics New Zealand, 2003). Data on termination service usage by non-resident Asian females in one abortion clinic increased from 12 percent in 1995 to 55 percent in 2002 (Goodyear-Smith and Arroll, 2003). According to the authors, the finding suggests inadequate sexual health education, especially contraception, and Asian women's view of men as responsible for contraception (Goodyear-Smith and Arroll, 2003).

Recently, the New Zealand Qualification Authority (NZQA) drafted a code of practice for accredited institutions to improve student care services. The code requires, where applicable, providing advice on accessing information on sexuality education, health promotion, and sexual and reproductive health services (Ministry of Education, 2003). However, Asian students may be reluctant to access this service. Findings in New Zealand and elsewhere indicate that discussing sexual health matters, including contraception, is often seen as culturally inappropriate in Asian cultures (Okazaki, 2002; Wyatt et al., 1999; Pequegnat and Stover, 1999; Baldwin et al., 1992; Cheung, 2004; The Asian Public Health Project Team, 2003).

Other than the studies that have been mentioned, there is a general lack of health studies and very little on sexual health focused on Asians in New Zealand. The few health-related studies which provide some data on Asians looked into body mass composition and smoking cessation. More recently, Ho et al. (2003) reviewed studies on the mental health of Asians in New Zealand. This study was conducted to know more about the knowledge and views of Asian sojourners on sexual health. The study explored three areas: awareness, knowledge and importance of health to Asian students; their main sources of information about sexual health; and the role of culture in seeking information on sexual health. 


\section{Methodology}

The Online Survey

Data for this paper came from an online questionnaire completed by 66 male Asian student sojourners registered at Waikato, Canterbury and Otago Universities. Since the investigators were men, the local ethics committee required that participants be limited to men. Suggestions from earlier studies that men tend to make decisions in heterosexual relationships among Asians was another factor in focusing on male Asian students. Given the sensitive nature of the topic, the study designed an Internet-mediated survey.

Survey participants were recruited in late November 2002 and March 2003 through international student offices at Waikato, Massey, Canterbury, and Otago universities. The study used their mailing lists to inform students of the study, and to invite them to participate. The letter described the research purpose, participants' rights, the researcher's contact details, and a link to the online survey on the web server of the Department of Psychology. An advertisement was also inserted in the Massey official international student newsletter, which has a circulation of 1,000. No hyperlink was provided from any other webpage to eliminate random access via internet search. Server records showed that the information page and survey form were viewed by 430 and 318 interested participants, respectively.

Interested students were asked to click on the invitation e-mail, which led them to a consent form, which describes the nature and purpose of the study, the rights and guarantees, the contact details of the researcher and supervisors, and an invitation to take part in the survey. Those wishing to participate were led to a link which stated that they had read and understood the invitation and guarantees and would like to participate, and eventually to the questionnaire. Completed questionnaires were stored on the website's server, which were transformed into an SPSS data file for further analysis.

The study developed its own questionnaire. Existing measures were not used because for the following reasons: most of them focused only on the physical or medical aspects of health; most were Western-oriented; and most measures do not include questions about participants' own concepts of health. Based on the literature review, a questionnaire was constructed to explore the following areas: general and sexual health attitudes, level of attention to health maintenance, intentions concerning contraception use, and social interactions involving discussion of general and sexual health. The questionnaire comprised 96 close- and open-ended questions. Non- 
parametric tests were used to analyze the data (Spearman's rho for Likert scale correlations, Friedman and Wilcoxon tests for mean rankings).

\section{Key Informant Interviews}

The project also conducted key informant interviews with seven health practitioners or educators who deal with Asian clients. Although invitation letters were sent out to many potential participants, we were able to interview health practitioners or educators in the Hamilton region. The recruitment and interview of key informants was carried out between February and March 2003. The main questions in these interviews were: the proportion of Asian student sojourners among their clientele, common concerns raised by their Asian clients, and the attitudes of their Asian clients toward general and sexual. All interviews were tape recorded, transcribed, and organized by theme.

\section{Results and Discussion}

\section{General Health Attitudes}

Almost all respondents saw their health as very important (53 percent) or important (38 percent). This is consistent with findings from a previous study (O'Connor, 2002). Reasons given why they attach importance to their health were for goal achievement $(n=19)$, happiness $(n=9)$, and health as having an intrinsic value $(\mathrm{n}=9)$. Likewise, most respondents ( 88 percent) reported that they paid some (58 percent) or much (30 percent) attention to their health. The correlation analysis showed that the higher the level of importance given to their health, the higher the level of attention they paid to their own health $($ rhos $=.63(65), p<.001)$.

Respondents were asked how often and with whom they discuss health-related matters. Based on mean rankings (the lower the value, the more likely the discussion with specific persons), Table 1 shows that mothers, girlfriend/partner and male peers were the people they discussed health-related matters with. Interestingly, doctors were often mentioned among the "other people" that they consulted. The role of teachers, whether male or female, seems minimal. The respondents' feelings of trust and closeness seemed to determine with whom they would discuss their health, since the range of people with whom they would do so was very narrow. Health practitioners and promoters need to be aware of these findings when working with Asian clients. 
TABLE 1

PERSONS WITH WHOM RESPONDENTS DISCUSS GENERAL HEALTH MATTERS

\begin{tabular}{lc}
\hline Person Consulted With & Mean Ranking \\
\hline Mother & 3.20 \\
Girl friend & 3.22 \\
Male peers & 3.73 \\
Other people & 3.90 \\
Father & 3.92 \\
Female peers & 4.78 \\
Female teachers & 6.60 \\
Male teachers & 6.65 \\
\hline
\end{tabular}

\section{Sexual Health}

Questions for this section probed into their level of knowledge about condom use and contraception, intention to use contraception and the importance of contraception.

The great majority of participants were aware that contraception was used for pregnancy prevention (98 percent), preventing HIV infection (97 percent) and preventing STD infection (90 percent). Hepatitis B prevention (73 percent) and inadequate protection due to incorrect usage (72 percent).

Sixty-seven percent of respondents considered contraception important (21 percent) or very important (46 percent). About three-fourths, 73 percent, reported intention to use contraception: 39 percent said they were absolutely certain; 32 percent claimed that they were quite likely to. Those who provided reasons mentioned birth control $(n=9)$ and maintenance of a stable relationship $(n=4)$. The correlation analysis showed that the more importance they attached to contraception, the higher the intention to use it (rhos-.56(51), $p<.001)$. The level of attention to general health was not correlated with intention to use condoms.

\section{The Role of Culture}

Most respondents (76 percent) reported that sexual health was not a common topic of discussion in their cultures. It was not usually discussed (38 percent) or discussed only when it is necessary (38 percent); 20 percent agreed that public discussion of the topic was accepted. The most common reason given was that cultural mores did not allow them to discuss such issues openly in the public domain $(n=22)$. When asked what topics in this area were talked about in their culture, responses included: contraception 

issues $(n=8)$, and STD issues $(n=4)$. Asked what is not talked about, some respondents mentioned sex $(n=6)$; sexual health, including STDs /HIV $(\mathrm{n}=4)$; and pre-marital sex $(\mathrm{n}=2)$.

This study's findings support previous studies (Okazaki, 2002; Wyatt et al., 1999; Pequegnat and Stover, 1999; Baldwin et al., 1992; Cheung, 2004) which found that while Asian males may be concerned about their health, including sexual health, they tended to discuss these concerns with few people, largely because their culture does not encourage public discussion of such topics. Other previous studies heavily emphasized the effect of gender discourse, in particular, masculinity discourse, on male general and sexual health attitudes (McKernon, 2002; Orr and Langefeld, 1993; Wyatt 1994; Yee et al., 1995; Amaro, 1995). These studies suggested that non-contraceptive use among males is associated with a risk-taking attitude, i.e., an attitude that does not value the importance of preventative approaches.

The low response rate in this study, despite several hundreds entering the website, is also an indicator of reluctance to discuss health matters publicly. The same observation was made by other workers in this field (The Asian Public Health Project Team, 2003; Zhang et al., 1999).

The reluctance of Asians to discuss sexual health in public also came out in the key informant interviews. According to the key informants, compared to their European/ Pakeha clients, their Asian male clients were very hesitant to consult; when they do consult, they are very reluctant to discuss health matters. One key informant observed that Asian clients tended not to disclose a previous medical consultation with another doctor. One informant quoted a common Chinese saying, "You'd rather shed blood than tears," to underscore the reluctance in discussing health problems. All seven key informants reported an even greater level of difficulty in discussing sexual health matters.

\section{Educational Influences}

About half of the survey participants (52 percent) had attended a sexual health education seminar at least once in their home countries; close to half (41 percent) had never undergone such seminar. Schools were the most common organizers of such seminars $(n=17)$, and the most common reason given for attending the seminar was to comply with school requirements $(\mathrm{n}=14)$. Sexual health in general, HIV/AIDS, STDs and reproductive health were the subjects covered, according to the small number of respondents who provided additional details.

Fewer respondents (15 percent) had ever attended a sexual health seminar in New Zealand; 76 percent never attended. The higher the level of 
TABLE 2

SOURCES OF INFORMATION ON CONTRACEPTION

\begin{tabular}{lc}
\hline Source & Mean Rating* \\
\hline Books/Magazines & 2.52 \\
Other sources & 2.56 \\
Friends & 2.58 \\
School & 3.45 \\
Parents & 3.89 \\
\hline
\end{tabular}

cultural acceptance of public discussion of sexual health in their cultures, the higher the likelihood of having attended sexual health education seminars in their home countries (rhos $=.33(61), p<.001$ ).

Key informants expressed concern that Asian sojourners had inadequate knowledge and information to maintain sexual health. This included inadequate understanding of contraceptive methods; they also tended to believe that oral contraceptive pills have bad side effects.

\section{Media Influences}

In response to the question "How much did the following influence your knowledge of contraception?" many participants (65 percent) cited printed media such as books and magazines as having a lot or much influence. Friends ( 41 percent) and other sources ( 29 percent) were also mentioned as significant influences. Schools and parents trailed behind as sources of information on contraception. The mean ratings are presented in Table 2 (the lower the value, the higher the frequency of seeking information from a specific source).

The results of the correlation analysis on these sources of information on contraception supported the patterns suggested by Table 2 . Books/magazines, other sources, friends were about equally important, but were significantly more so than school (Wilcoxon's $\mathrm{z}=-3.94, p<.001$ ), which in turn was more important than parents $(\mathrm{z}=-2.69, \mathrm{p}<.01)$. Those who rated media influences, such as books/magazine (rhos $=.39(57), \mathrm{p}<.01)$ and TV programs /websites (rhos $=.49(27), p<.01)$, more highly were more likely to report intention to use contraception.

Compared with other studies, the findings of Cheung ( 2004) concerning Asian students in New Zealand, and of McKernon ( 2002) on "average" New Zealand males, also point to a preference for printed materials, TV programs and the web as sources of information. Educational promotion through these media, especially the web, would be effective with both Asian 
sojourners and New Zealanders in increasing their level of awareness of sexual health practices.

\section{The Language Barrier}

Communication difficulties due to insufficient language skills was one theme that came out in the key-informant interviews. According to the key-informants, language often made it difficult to obtain the information essential to diagnose correctly.

\section{Conclusion}

Although this study focused solely on Asian male student sojourners, it provides a first step in investigating health attitudes and cultural influences on Asians in New Zealand. The study underscored the need to promote sexual health education to Asians in New Zealand. Given their reluctance to discuss sexual health matters publicly, personally accessible media, such as the Internet and print media, may be the optimal means to deliver information while maintaining the privacy of users. Since Asians are not a homogeneous group, future research should focus on sub-populations, such as national groups. Future researchers should also aim to obtain a more representative sample, and to devise means of probing more deeply into the topic, attempting to obtain information concerning actual sexual health behavior if possible.

More learning opportunities and information would improve the awareness of Asians about health in general, and sexual health, in particular. All key informants agreed that education is key to resolving these issues, although they recognized that resource issues, the language barrier, and the difficulties of changing culturally based attitudes pose challenges. Health education, thus, has to be cost-efficient, multilingual, and culturally appropriate. Providing health education in general and sexual health in particular are needed to improve Asian students' health and well-being during their stay in New Zealand. Such a program can also benefit other Asian residents in New Zealand, but until more is known about what works best for whom, effective changes will be difficult. 


\section{REFERENCES}

Amaro, $\mathrm{H}$.

1995 "Love, Sex, and Power: Considering Women's Realities in HIV Prevention," American Psychologist, 50(6):437-447.

Baldwin, J. D., S. Whitely and J. I. Baldwin

1992 "The Effect of Ethnic Group on Sexual Activities Related to Contraception and STDs," Journal of Sex Research, 29(2):189-206.

Cheung, V.

2004 "Risk and Protective Factors Influencing Sexual Health Behavior among Chinese University Students." Paper presented at the Inaugural International Asian Health Conference - Asian Health and Wellbeing: Now and Into the Future, School of Population Health, Auckland University, 4-5 November.

Goodyear-Smith, F. and B. Arroll

2003 "Contraception Before and After Termination of Pregnancy: Can We Do it Better?" The New Zealand Medical Journal, 116(1186).

Ho, E., S. Au, C. Bedford and J. Cooper

2003 "Mental Health Issues for Asians in New Zealand: A Literature Review." Hamilton: Migration Research Group, Department of Geography, University of Waikato.

McKernon, S.

2002 "Abducted by Aliens: Heterosexual Men and Sexual Health." In The Life of Brian: Masculinities, Sexualities and Health in New Zealand. Edited by Worth, A. Paris and L. Allen. Dunedin: University of Otago Press.

Ministry of Education

2004 "International Students in New Zealand schools at 1 July 2004." Wellington: Ministry of Education.

2003 "Code of Practice for the Pastoral Care of International Students - Revised December 2003." Wellington: Ministry of Education.

O'Connor, A. M.

2002 "Young Pakeha Men's Conceptions of Health, Illness and Health Care." In The Life of Brian: Masculinities, Sexualities and Health in New Zealand. Edited by H. Worth, A. Paris and L. Allen. Dunedin: University of Otago Press.

Okazaki, S.

2002 "Influences of Culture on Asian Americans' Sexuality,"Journal of Sex Research, 39 (1):24- 41.

Orr, D.P. and C. D. Langefeld

1993 "Factors Associated with CondomUse by Sexually Active Male Adolescents a t Risk for Sexually Transmitted Disease," Pediatrics, 91(5):873-879. 
Pequegnat, W. and E. Stover

1999 "Considering Women's Contextual and Cultural Issues in HIV /STD Prevention Research," Cultural Diversity and Ethnic Minority Psychology, 5(3):287-291.

Statistics New Zealand

2003 "Abortion - additional tables," Vol. 2003. Wellington.

The Asian Public Health Project Team

2003 "Asian Public Health Project Report February 2003." Auckland: Ministry of Health.

The New Zealand Herald

2003 "Asian Abortions Rocket," 3 April.

Wyatt, G. E.

1994 "The Sociocultural Relevance of Sex Research: Challenges for the 1990's and Beyond," American Psychologist, 49(8):748-754.

Wyatt, GI., A. Moe and D. Guthrie

1999 "The Gynecological, Reproductive,-and Sexual Health of HIV-Positive Women," Cultural Diversity and Ethnic Minority Psychology, 5(3):183-196.

Yee, B. W. K. et al.

1995 "Panel IV: Risk-taking and Abusive Behaviors among Ethnic Minorities," Health Psychology, 14(7):622-631.

Zhang, K., D. Li, H. Li and E. J. Beck

1999 "Changing Sexual Attitudes and Behaviour in China: Implications for the Spread of HIV and Other Sexually Transmitted Diseases," AIDS Care, 11(5):581-589. 